\title{
Standards dynamics and industrial organization in the mobile telecom sector*
}

by: Eric J. Iversen (NIFU STEP Studies in Innovation, Research and Education- Oslo, Norway, and the Australian Innovation Research Centre at the University of Tasmania, Australia); and Richard Tee (TNO, dept of ICT and Policy / University of Brussels (VUB), Studies on Media Information and Telecommunications (SMIT) Netherlands)

\section{autobiographical note}

Eric J. Iversen is a researcher at NIFU STEP Studies of Innovation, Research, and Education in Norway, where he has worked in the field of innovation and the economics of technological change since 1994. His work centers on the 'framework conditions' of technological change with special focus on quantitative and qualitative analyses of standardization, IPRs, and their interrelationship. His project work has mainly catered to Norwegian government agencies, the World Intellectual Property Organization, and the EU. $\mathrm{He}$ is on the editorial review board of the International Journal of IT Standards \& Standardization Research, and is currently involved in two European Framework projects on standardization. Eric is from 2006 a research fellow at the Australian Innovation Research Centre at the University of Tasmania, Australia, where he is working on the changing role of the patent-system in small open economies.

\section{autobiographical note 2}

Richard is a researcher at the Dutch TNO research institute, unit for ICT and Policy and also works for the University of Brussels (VUB) at the centre for Studies on Media Information and Telecommunications (SMIT). His research has been mostly concerned with technological stabilization processes, particularly from the perspective of dominant designs, as well as usercentered approaches. Currently he is involved in a multi-year research project on broadband and mobile services of which the main goal is the creation of a business modeling framework taking into account relevant user, standardization and policy dimensions. 


\section{Introduction}

"In a very real sense, organizational form in the network economy has itself tilted towards loose networks of alliances rather than clear boundaries between hierarchical organizations." (Shapiro, 1999: 14) ${ }^{1}$ The tilting of this organizational landscape is reflected to a significant degree in the changing modes in which standardization activities are being organized in the turbulent area of mobile communication systems, where standards are central. The change is particularly evident in the many false starts of the long awaited move to $3 \mathrm{G}$. Instead of an orderly generational succession of comprehensive and concerted standardized systems, a considerably more fluid and multifaceted landscape has emerged.

This paper starts from the observation that the changing landscape has confronted industry incumbents with a need to reassess their competitive positions, their organization processes, and their potential paths of development. In short, it has put a premium on the 'dynamic capabilities' (Teece et al, 1997; Teece 2000) of these firms and the innovation systems they are embedded in. This challenge is particularly relevant to the need of Nordic actors, who have largely built their capabilities and their fortunes by managing the transition from first generation NMT to the unprecedented international success of the second generation GSM system, to adapt to the changing competitive environment. Following Glimstedt (2001), we take an updated look at the changing organization of the dynamics of technological standards in the mobile environment.

To set up a discussion of the challenges faced by the Nordic area that can communicate with the other papers in this special issue, this paper focuses on what the changing standards framework can tell us about overall dynamics. The argument is that changes at the institutional level of standardization and the way they articulate with the wider dynamics of the mobile telecoms sector are to a significant degree shaping the further development of the sector. An example of this is the case of the Symbian alliance in which Nokia, and other in part competing companies have created a coalition around common interests in order to create 'standard' operating systems for mobile handsets. The aim is to analyze key changes in the institutional setting for standardization and to discuss what they indicate about further developments of the mobile sector.

\section{Nordic, Global, Universal: The limits of intergenerational leveraging}

When the re-regulation of the telecoms market started in the 1980s and 1990s, it catalyzed a fundamental reorganization of the telecoms industry. The reorganization from the PTT centric monopoly-players paradigm coincided in Europe with an explicit change in the organization of standardization activities. This was not a coincidence but rather testified to the recognized fact that formalized standardization activities are key to the telecoms industry (cf. Iversen, 1999). The standardization activities of the CEPT, the regulators body that reflected the interests of the national telecom operators (the then PTTs) in Europe, were thus handed over to ETSI in the late 1980s. This hiving off of CEPT's standardization activities thus introduced an institutional framework in which the organizational rules were fundamentally different, including a significantly more open membership which allowed for the participation of vendors, users, and other stakeholders.

It is worthwhile recalling this transformational era of the telecoms industry, and the key role

\footnotetext{
${ }^{1}$ Shapiro, 1999. Competition Policy in the Information Economy. http://faculty.haas.berkeley.edu/shapiro/comppolicy.pdf.
} 
standardization played in the changing industrial dynamics, when focusing on the current reorganization of the mobile telecoms sector and the changing role standards now play. This period signalled a substantial change in the positions of incumbent monopolists PTTs. The idea that mobile communications - and the extensive standards that underpin them- develop in generations $(1 \mathrm{G}, 2 \mathrm{G}$, etc) accompanied this substantial change in the market conditions of the industry. The popularized generational model served to promote a sense of orderly development in technological conditions among the installed base. This stability was particularly attractive at the height of the success of the GSM standards, coinciding with the interests of established stakeholders to project their current success into future markets as they addressed already recognized improvements in the $2 \mathrm{G}$ architecture.

At least since the last meeting of GSM created a Sub-Technical Committee to study UMPTS in October 1991, a different set of standards dynamics has increasingly challenged the stability suggested by this generational model. Here the role of standards has been changing apace. There are several aspects of this transition to call attention to here:

- The first is that it initiated a defining period in the reorganization of the telecoms industry in general and the mobile telecoms industry in particular.

- The second is that the organization of standards activities was a chief element of this reorganization, with the launch of $2 \mathrm{G}$ systems based on the GSM standards effectively laying the basis for market, technological and competitive conditions in the mobile telecoms sectors for years to come.

- The third is that Swedish and Finnish firms, especially Nokia and Ericsson, leveraged their experience in the early Nordic collaboration around the 1 G NMT standards into the $2 \mathrm{G} \mathrm{GSM}$ standards, propelling them to the top of the nascent mobile telecoms industry. (Edquist et al., 1998)

A fourth observation is that the over-reliance on this type of "intergenerational leveraging" from one standardized technological system to the next is a risky industrial strategy. There is a substantial risk of identifying the long-term development of one's firm-level capabilities with the expectancy that the dominant technological trajectory of the mobile telecoms industry will persist along a reasonably protected path plotted by the orderly development of compatibility standards. The path may well lead to a lock-in of one's capabilities to an outmoded standard.

\section{Industry organization and industrial dynamics}

A traditional approach to industrial organization focuses on the impact of the reorganization to market structure, especially the impact on monopoly. The re-regulation that catalyzed changes in the organization of the telecoms in the 1980s and 1990s initially addressed the monopoly position of telecom operators or PTTs. In Schumpeterian terms the transition set about a re-organizational process that led to 'new combinations of productive means' and, in doing so, substantially contributed to 'economic development'. (Schumpeter, 1934: 64)

But the changing market structure has been one of a wider set of concerted factors. The transition of the mobile telecoms industry has pervaded all levels of the innovation system with major changes evident in technology, markets and commercial conditions, as well as in institutional and regulatory frameworks. Together these have contributed to the reorganization of the telecoms industry in general which has been particularly dynamic in the mobile telecoms sector. 
Here the question of the organization of the industry becomes one of the factors shaping its dynamics (e.g. Carlsson, 1987). These changes substantially involve the co-evolution of technology, market structure and institutions (Nelson, 1994) ${ }^{2}$. Earlier studies have indicated the range of factors involved in the industrial dynamics of related sectors. These include; Bresnahan \& Malerba (1999) ${ }^{3}$ which looked at the computer industry in general, Kim \& Lee (2001) which looked the DRAM industry ${ }^{4}$, and Abbate (2000) which looked at the internet with a specific focus on the specific influence of the standardization process. In the case of the mobile telecom industry too, we see the changing standards system as one of the hallmarks of the industrial dynamics at work.

\subsection{Standardization: balancing flexibility and stability}

A question that underlies industrial organization is how emerging technologies co-evolve with the demand for new applications and services. This core question involves the coordination of two complex sets of dynamics which are intimately linked at the level of the socio-economic system. The first involves market dynamics which emerge as demand structures form to select and to price emergent technological solutions. This process of selection coordinates the consumption decisions of different actors who hold different sets of preferences (and different endowments etc.). The second set of dynamics involves technological change, which underlies the evolving production structures in the economy. Although inseparable from market dynamics, the generation of new technology grows out the technological capabilities of actors and their strategic decisions.

In this dynamic environment, the organization of standardization activities has emerged as an institutional framework to support technological generation and the market selection processes where market coordination is weak. In general, "standards result from the intricate interaction of company business strategies, standards committee activities, government interventions, and processes of market diffusion, and they are rooted in the perceived technical requirements for developing, manufacturing, operating or using devices that are meant to inter-work with others." (Schmidt \& Werle,1998: 33) Gaillard (1934) observed seven decades ago some of the essential aspects of standards in industrial dynamics:

- a standard provides a, "temporary constant level of requirements or conditions under which the practical industrial application of a basic idea will be possible, technically as well as economically;

- a standard coordinates factors, "whose harmonious working together is required for complying with the conditions determined by that temporary level of stability."

- $\quad$ it is important to, "leave sufficient facility for making a shift from one temporary level to the next one, if and when this becomes necessary due to progress made in the art." (Gaillard, 1934: 14)

In general it can be said that such temporary periods of relative stability are important in order to "limit the tyranny of combinatorial explosion" (Metcalfe \& Miles, 1994) and, in doing so, reduce essentially non-functional duplicative research efforts. In short, recognized standards allow market and technological dynamics to coalesce around specific technical or

\footnotetext{
${ }^{2}$ RR Nelson The co-evolution of technology, industrial structure, and supporting institutions. Industrial and Corporate Change, 1994

${ }^{3} \mathrm{http}: / /$ www.stanford.edu/ tbres/research/ccc7.pdf

${ }^{4}$ Kim, CW and Keun Lee. (2001)Innovation, Technological Regimes and Organizational Selection in Industry Evolution: A "History Friendly Model" of the DRAM industry. http://dasan.snu.ac.kr/ ecores/activity/paper/no.46.PDF
} 
organizational 'givens'. They are designed to provide a framework that improves interaction across the frontier between supply and demand. In this setting, standardization becomes integral to the larger evolutionary process in which actors try to negotiate at the interface between technological learning (in technological regimes) with market regimes (which describes the competitive landscape). (Dosi et al., 1995). Standardization is an important factor that shapes not only the technological design of the system but also 'organizational design' of the firms as well as that of other industrial actors (Langlois, 2003).

Langlois (2003) indicates that standardization processes have become important institution to solve coordination problems and, in doing so, play a central role as a marketsupporting institution to facilitate positive aspects (such as dynamic learning) of such a reconfiguration: "In many cases, the visible hand has indeed been socialized into technical standards that permit external mechanisms of coordination and reduce the need for rich information transfer." (Langlois, 2003; 376) 5 Coordinating these activities allows firms to commit to long term paths of competence development. (Teece et al, 1997) ${ }^{6}$

But it also involves the risk to perpetuate path-dependency and thereby to 'lock-in' processes the development of firm-level learning and industrial change along suboptimal trajectories. ${ }^{7}$ Following Langlois' modularity argument, a main question turns at the level of the economy to how 'stuck' 'rigidly bound networks of complementary capabilities' can become and how easily (with lowest costs) alternative routes can be made away from them towards socioeconomically more attractive technological trajectories. Following the coordination dilemmas in standards setting, a situation of 'inferior modularization' might result from cases of excessive inertia leading to dominant systems being left in place too long or, alternately from making blind or hasty transitions when 'design rules are in flux' (see also Anderson \& Tushman, 1991: below).

\subsection{The organizational of standardization}

The way the standards process is organized is integral to technological and market dynamics. In the industrial organization tradition, the literature dealing with standardization tends to differentiate anticipatory standards formation processes depending on whether they take place in "pure market", in "committee" coordinated, or "hybrid" structures (Farrell \& Saloner, 1988).

The particular institutional set-up for the standardization activities reflects - and will tend to be articulated to- a set of market factors (e.g. organizational and strategic considerations) and technological factors. These include the original positions of key stakeholders, identifiable market dynamics (e.g. emerging technological or geographical markets) that may be shaping the product and/or service environment to which the standard applies, including instabilities and other motivations for change. Other aspects that will shape the dynamics of the standards at both levels might involve: investment, enterprise structures and actor topologies, market and revenue structures (for commercial enterprises), organizational and resource structures (for public services), critical asset dependencies, instabilities and motivations for change, and established links with standards suppliers.

\footnotetext{
${ }^{5}$ Quoted in Rejoinder $(2004 ; 5)$. He stresses that this involves many cases and not necessary most and far from all.

${ }^{6}$ Draw implications for Nordic actors in changing horses...As this takes place, actors, such as incumbent Nordic stakeholders, are confronted by strategic decisions as they commit $\mathrm{t}$

${ }^{7}$ Cf. David \& Steinmueller, 1990: The ISDN Bandwagon is coming: who will be there to climb aboard?"
} 
But the standardization framework is itself not immutable in this dynamic environment. The development of standards in the mobile telecom sector is part of the overall evolution of the complex socio-technological systems. As part of it, the standard subsystem continually adapts to the overall industry dynamics (involving technological factors, market factors, regulatory factors, etc). In this sense, standards bodies evolve as functional institutions that serve to coordinate individual technologies into complex technological systems (cf. Schmidt, 1992). The dynamics reflects a larger evolutionary process that is arguably reshaping the institutional basis for standardization within the volatile telecoms markets.

Our argument is that, in the mobile telecoms sector, the change in the organization of standardization activities is transforming itself as a function of the changing industrial dynamics. The implication is that stakeholders must adapt with the changing standardization environment in order to position themselves and their capabilities. Stakeholders such as the Nordics which were hugely successful in leveraging their capabilities within the generational developments from $1 \mathrm{G}$ to $2 \mathrm{G}$. In light of the current situation in which mobile networks are set to become more consistently global, such stakeholders are seeing the need to diversify their technological and market capabilities to ensure that they are not left in at a deadend as the industry engages in a series of pitched battles for the next generation technologies in the IMT-2000 suite.

The need to diversify their technological and market capabilities substantially entails the need to review their involvement in standards processes. The resulting strategic behavior is translating into a substantial reorganization of standardization processes not least in the mobiles environment. This is taking place in a more general environment in which there is an increase in number and variety of standards-setting bodies, with a growing range of activities and deliverables. And thus there is an increasing potential for linkages and collisions between different bodies. The established voluntary standards bodies have thus seen an increasingly competitive market (see David, 1995) in part due to converging technological areas, increased internationalization, and the effects of reregulation.

An important ingredient in this changeable environment is the emergence of new organizational forms, particularly different forms of purpose-built coalitions and consortia. The consortium-based organization of standardization activities places more emphasis on flexibility than institutional stability and thus may reflect better the direction of interesting market opportunities (Hawkins, 1999). A complementary aspect of the changing "landscape of standardization organizations," is the evolution of processes of coordination as well as competition between bodies. (Werle, 2000) This involves not only the coordination of established standards-development bodies, which we will see more in the aggregation of the rival G3PPs, but also between established bodies, such as ETSI and consortia, such as Parlay. (see below)

What has emerged can be called a convergence towards, "hybrid selection processes, where both market competition and negotiation play a role." (Vercoulen \& Van Wegberg, 1999: 1) Marks and Hebner (2004) find this sort of dynamic between formal and informal standardization activities in the case of Ethernet where they quote Bob Metcalfe, Ethernet's primary inventor, as characterizing the successful Ethernet technology as more of a business model than a standard. Metcalfe said to CNET in 2003 that:

It's based on de jure standards with proprietary implementations of those de jure standards, and it is unlike open source in that competitors don't give their intellectual property away. The competition is fierce, but there is a market ethic that products will be interoperable. And 
the standard evolves rapidly based on market engagement in such a way to value the installed base. There is a heavy value placed on sustaining and maintaining the installed base. That's the Ethernet business model." (CNET News.Com "30 years of Ethernet Gains," 21 May 2003. Cited in Marks and Hebner (2004). The Standards Edge: Dynamic Tension. S Bolin (ed).

We see some of the same tendencies in the mobile telecoms industry where the traditional focus has been for a number of reasons on formal committee-based (or de jure) processes. One aspect of this is the changing role that regulators are seen as 'giants', which may be 'blind' (David, 1986) or just influential (Funk and Methe, 2001), in the shaping affecting standards processes. ${ }^{8}$ Whereas the latter authors argued for a need to focus on the role of governments in the development of mobile telecoms standards, we see a need to focus more on the emergence of market-based coordination activities, such as consortia.

The paper will therefore focus below on a case of a symptomatic attempt by actors to establish 'dominant design' technologies in the technological cycle along less traditional lines. The case we will look at is that of Symbian, a joint-venture of competing companies that was incorporated into a company to develop, spread, and hopefully dominate operating systems for handsets. Before turning to the case we look at the often overlooked literature on dominant design.

\subsection{Pure market standards and the drive towards dominant design}

Much of industrial organization work involving standardization has focused on the pure market variety of standards. One relevant area of this literature has looked at technology life cycles. In this context technological standard can be associated to the "single architecture that established dominance in a particular product class" and, as such, has an affiliation with what Abernathy and Utterback (1978) called "dominant design". The market-based drive towards dominant design involves several stages during which a range of different actors coalesce around single technologies to the exclusion of others; in later writings it is described as a 'satisficer' of the different technical possibilities and market choices (Utterback, 1994). Dominant designs of technologies emerge at the end of technological cycles, before a new period of technological discontinuity initiates a new cycle.

If competition between technologies is all about "the creative destruction of rigidly bound networks of complementary capabilities" (Langlois, 2004; Langlois \& Robertson, 2001), such technological cycles involve the creation of 'networks of complementary capabilities' among actors which achieve market dominance, and their subsequent destruction as in periods of technological discontinuity. In between there is an era of ferment, followed by an era of design competition, followed by a period of stability typified by incremental change. (see Anderson and Tushman, 1991)

An alternative approach, which is similar to the technological regime idea (Nelson and Winter, 1982; Winter, 1984), involves the notion of "technical agenda" (Clark, 1985) or the design space in which producers of a technology operate. Once the technical agenda is closed, movement will take place down the design hierarchy (referred to as the "regular" phase), which is concerned with enhancing and refining the value and appeal of the product. In other words, it is the confirmation of a trajectory. Conversely, movements up the hierarchy

\footnotetext{
${ }^{8}$ The role of government is amply demonstrated in the cases of $1 \mathrm{G}$ and $2 \mathrm{G}$ standards especially in Europe where public actors played a significant role. (see e.g. chapter 2 of Hillebrand (ed), 2002)
} 
(sometimes called "de-maturity") are associated with movements away from the existing design. Aside from particular terminology, common in each conceptualization is the idea that after a period of experimentation among a number of competing designs an unstable, chaotic, and widely interpretable situation is followed by another, more stable period, when variety is reduced to a single or a few general interpretations of the technology.

The studies of dominant design in the case of the car industry, aircraft, and later cement, glass and minicomputers indicates that a technology will converge toward a single - dominant design according to some selection process. The ability to generalize from the studies that have demonstrated the appearance of single dominant designs has been under discussion. It becomes necessary to distinguish between different levels of the system, in particular between the overall system level and subsystem level. A technology, which can range from simple artefact to complex system, is conceptualized as consisting of multiple levels. Often, research describes the establishment of dominant designs on a subsystem level (such as engine type for cars) but implies that the dominant designs is found on the entire system level (e.g. automobiles). For this reason it is helpful to distinguish between overall system level, and (multiple) layers of subsystem level. In turn, subsystems consist of components, which can be subsystems themselves. Analyzing dominant designs from a systems point of view allows for a more explicit operationalization of the concept and its boundaries. It is proposed that as long as the core components (or core subsystems) are consistent, one can speak of a dominant design in the overall system.

Using a systems approach to dominant designs is not new. The added value of this approach lies in the formalization of how to distinguish between core and periphery subsystems. In order to make an explicit distinction between core and periphery Murmann and Frenken (2002) introduce the notion of pleiotropy. Pleiotropy is a concept borrowed from biology, where it is used to denote the number of traits that are affected by a particular gene. In this context one might say the pleiotropy gives an indication the of the structural embeddedness of a component within the network.

An example, given by Murmann and Frenken is a design architecture with three technical characteristics (e.g. type of engines, type of tires, type of steering device) and two service characteristics (e.g. speed and safety). In the example, two technical characteristics have a pleitropy of one, while the other has a pleiotropy of two, since it affects on two service characteristics and the others only on one. In this case the i2 example will be less likely to change, given the greater risks involved for the overal functioning of the system, since a change in i2 might bring about an improvement in one service characteristic, but a decrease in another. Similarly we can think of technical characteristics in the mobile phone domain (e.g. battery type, display type, operating system, chipset etc) and service characteristics (e.g. messaging, multimedia, and gaming capabilities, size and weight of the device etc) that will differ in terms of pleiotropy.

Distinguishing between core and periphery components allows us a more uniform understanding of how we might define the establishment of dominant designs. They may converge on one level (e.g. messaging protocols, network type) while diverging on other dimensions (e.g. operating system, display type or size). The main question is what constitutes core components and what are the periphery components. Rather, as can be witnessed by the way actors are momentarily dealing with various platforms, the establishment of core subsystems or components - and subsequently the often less desirable periphery - is a negotiation process between the actors involved. Depending on factors such as the actors' 
power and established linkages, components will shift towards or away from the center of the overall system, thereby establishing an order on which control of the overall system is based.

\section{Mobile telecoms and the changing role of standards}

The immanent success or, alternately, the swift demise of $3 \mathrm{G}$ has been repeatedly heralded since work started in the early 1990s. The question that meanwhile has persisted for the Nordics, and the network of complementary capabilities surrounding them, since the early 1990s when steps were taken in Europe (ETSI) and internationally (ITU) to plan for the next generation, is to what degree they might still be able to rely on 'intergenerational leveraging' to build on their experiences and to strengthen their position in the ever more international mobile telecoms industry.

The probability of a smooth transition between $2 \mathrm{G}$ and a $3 \mathrm{G}$ environment solely based on a follow up of GSM (ie. UMTS) dissipated through the 1990s. Instead of a single line of inheritance, the transition from $2 \mathrm{G}$ to $3 \mathrm{G}$, already envisioned in mid 1980s, involved several preliminary upgrades from existing platforms (e.g. GPRS, Edge) and a set of standards battles. The first setback that the Nordics faced was when the joint W-CDMA proposal wound up in a battle in Europe with the alternative air-interface proposal based on time division CDMA. The resulting combination of Frequency Division Duplex (FDD) and Time Division Duplex (TDD) modes into the Universal Terrestrial Radio Access, UTRA. However, the key event was the split between two $2 \mathrm{G}$ regimes with distinct $2 \mathrm{G}$ legacies accompanied by a selection of radio access technologies. This split was the 3rd Generation Partnership Project (3GPPTM) based on a coordinated GSM-based proposal and the 3rd Generation Partnership Project 2 (3GPP2) based on evolved ANSI-41 network.

In this process standardization processes have been organized in novel ways to facilitate international transition to a $3 \mathrm{G}$ environment. The split in the $3 \mathrm{G}$ environment has taken place under the common umbrella of the longstanding beacon of the International Telecommunications Union (ITU)'s IMT 2000 initiative (earlier Future Public Land Mobile Telecommunications Systems initiative). The umbrella, and the political pressures that were there to keep it up, have served to diffuse the standards battle and to allow the two camps to evolve separately but still with a degree of compatibility.

Glimstedt (2001) suggested that this method of 'packaging global standards' and the fact that it allows 'for modular innovation within standardized interface' would be a contributing factor to the, "market for mobile cellular communications ...to take off in a very big way." (Glimstedt, 2001; 1) Similarly, Funk \& Methe (2001) suggest that the signal effect of government involvement in mobile communications standards help to solidify nascent markets. So far, of course, $3 \mathrm{G}$ cannot yet be said to have taken off in a very big way. Much less dramatically, 3G standards have been finalized and updated several times (The 3GPP standards are in revision 6), infrastructure has been rolled out, and handsets are on sale providing ' the real $3 \mathrm{G}$ experience' (ETSI press release, July 2005). To address the lag in the development of services to fill this experience, links have been made to other standards bodies, especially Parlay, a consortium. (see Iversen \& Tee, 2005)

While the market has yet to 'take off', a drawn out standards-war thus seems to have been averted in this internationally coordinated standardizations efforts. This is primarily the coordination within the ITU, and between it and two clusters of standards bodies, primarily those involved in the two 3GPPs. Coordination however extends to others, for example with 
the formal link with the consortium, Parlay. Whereas, Shapiro \& Varian (1999) indicate that winning classical (market) standards wars often entails building alliances with other companies to promote the new technology, the case in this international hybrid environment places a premium on standards bodies building up alliances. This is not least a mode to shape the anticipations of consumers and to reinforce the allegiance of the relevant installed bases.

\subsection{Dynamics of the Symbian 'standards'?}

The case of Symbian involves a strategy to build alliances in the current environment. The case is symptomatic of the current flux of the standards environment and it illustrates some major changes in the mobile telecom industry evident in technology, markets and industrial structures. The premise is that Symbian represents a mode of organizing a quasistandardization coalition whose dynamics indicate aspects of the emerging mobile telecoms industry. Drawing on Schmidt \& Werle, we review where the process took place, why standardization activities were initiated, how different stakeholders were involved to influence or 'shape' the standard, and what the outcome was and how it related to product (or service) structures. This allows a window on the strategies of one Nordic player, Nokia, and its interactions in the mobile market.

Symbian involves an operating system for mobile handsets and its user interface (Symbian).

- type of standards: incorporated alliance or quasi-consortium (Symbian).

- maturity of markets: Symbian adapts a new technology and updates strategically to interwork with emerging standards.

- Intended effect: Positioning itself in the emerging market for handset operating systems. Particularly avoiding other the cross-technological leveraging dominance from other markets (Microsoft in OS)

- Degree of specification: to minimal common ground as in Symbian.

- Impacts: ca. $5 \%$ of the overall mobile handset market (Symbian) ${ }^{10}$

This case represents a special type of dynamics in the market for standards which is significantly unlike the technological coordination involved for example in the GSM case. Consistent with tendency to diversify standardization activities, the actors behind Symbian went outside the traditional standards environment. In this case, the founding actors - which compete in other markets - set up a company substantially based on the technology of one of the parties. The joint-venture mode to adapt an existing technology to the needs of a set of actors provides a distinct approach where the aim is to set a broadly applied standard. At base this mode attempts to provide maximum control over development (a company) while attempting to promote a high degree of coordination in what was expected to become a very competitive environment (competitive companies inside the alliance, a larger competitor outside).

The creation of alliances, although not new, illuminates an important area of the changing standards market. A defining aspect of this platform to promote 'standards' is partly due to the technology, an operating system for advanced mobiles which entailed a certain convergence of highly contested technology markets (PCs and mobiles). Alliance building here has been seen as a 'standards war' between leveraging of the partner technologies into

\footnotetext{
${ }^{9}$ Relies on thesis (Tee, 2004) and an earlier version in the ESA paper (Iversen \& Tee, 2005).

${ }^{10} \mathrm{http}: / / w w w . t h e r e g i s t e r . c o . u k / 2005 / 02 / 01 /$ mobile_devices_q4_04/
} 
the operating system for smart phones while avoiding Microsoft's bid to leverage its technologies into this market. But the way the Symbian alliance was founded and the way it has developed since substantially reflects changes in the strategic landscape (the market regime). These changes lay basis for a different set of standards dynamics.

\section{General dimensions}

Symbian was formed June 1998, initially as a joint venture between Psion, Nokia and Ericsson. One of the main assumptions behind the alliance was that as mobile handsets were becoming increasingly more powerful, it would be beneficial to the actors involved to have a standardized technology (OS) on which it could further develop. Furthermore, it was thought that as mobile handsets and PDA's tended to converge, a strategic formation was considered a prerequisite to effectively compete against rival companies on the OS market (i.e. Microsoft).

\section{Involved Actors, Motives \& General Strategies}

The initial distribution of the shares entailed Psion holding 40 percent of the shares and the remaining 60 percent being shared equally between Nokia and Ericsson. However, already at the company's launch Motorola had signed a memorandum of understanding to become a Symbian partner. When this was officially put into place Motorola's share taken from Psion's, with the three telecom vendors each having a 23.1\% stake. ${ }^{11}$ Matsushita (Panasonic) joined May 1999, in April 2002 Siemens took part, and Samsung joined February 2003. Earlier on, questions were asked whether U.S. based software companies such as Microsoft or Sun would perhaps join in the future, but this was not foreseen, stating that all major markets (Europe, U.S., Japan and South Korea) were already represented. ${ }^{12}$ There were probably other motives behind this as well. From the start, Symbian was considered to be set up at least partly out of strategic reasons: for most of the vendors, having Microsoft supply a mobile operating system was not regarded as an attractive prospect.

Since then, the alliance has undergone a number of important changes in terms of member composition. Two events in particular are regarded as crucial events in the group's existence. First, there was the departure of Motorola which besides giving up its financial stake in Symbian, subsequently announced it would license Microsoft's Windows Mobile for Smartphones (WMS) platform. Next Psion opted to sell its stake, because of financial reasons. The subsequent plans of Nokia to take over Psion's part were received critically by the industry. It was taken as a sign that the alliance would evolve into a Nokia vehicle rather than a vendor neutral platform provider as was originally conceived. For Symbian as a supposedly handset neutral alliance, this is not necessarily an advantage, since it jeopardizes the idea of being vendor agnostic, and thus the willingness of other vendors to commit to or license the platform (on the other hand, the investments and commitment of Nokia have greatly benefited the alliance as well) Besides the ownership issue, Nokia has been most influential in terms of providing the GUI technology for the OS.

\section{Coalition: the rise of quasi-standardization}

In the case of the alliance, licensing becomes the vehicle to disseminate the product as widely as possible. Symbian has pursued this dissemination process almost as a standards consortium would. It has taking pains to disseminate the technology as widely as possible, while stressing openness and neutrality. The exact license fees of the GUIs have not been officially disclosed but are said to be in the similar price range as the license cost of the OS itself. If true, this

\footnotetext{
${ }^{11} \mathrm{http}: / /$ www.computerwire.co.uk/market.watch/5FF75ED112CF972380256BD50054C8DC?Open\&Highlight=2 ,symbian

${ }^{12}$ Cohn (2001)
} 
approach seems to downplay commercial concerns in favour of improving take-up.

Symbian's approach to licensing involves two dimensions: the first - relatively simple - one is getting its partners to use the OS in a range of their own devices. Since all have investments in the company, the vendors have an interest to use the product in a number of their handsets. The second, more challenging, task is getting the product licensed to other makers. The uptake in this area is perhaps a much better indication of the actual need for the Symbian OS. Nokia is responsible for around $70 \%$ of Symbian handsets, all based on the Series 60 platform. Development of Series 60 handsets by other device makers has taken very long, and releases have been very infrequent. SonyEricsson does regularly update their Symbian line, though all of these are, at the moment, high end phones.

Symbian has created a number of other programs alongside its basic partnering structure. ${ }^{13}$ These programs include:

- The Companion Technology Program, a program set up for developers who implement technological solutions that extend and complement the Symbian OS, in order to ensure synchronization between the developers and the release of a new OS.

- The Symbian Enterprise Advisory Council, an institute focusing on the enterprise market that has been set up to improve communication and information sharing among key partners in technical, marketing and business development areas.

- The Platinum Partner Program, which comprises a number of different areas, including partners in the area of technology, tools, training, alliances, semiconductors, competence centers, and network operators. These partners are able to work closely together on issues which include hardware architecture, GUI design, value-added applications, services and content.

The support of software and application developers is important to any platform, and the relevance of this can be witnessed by the goals of the first and third programs. All of these instruments can be interpreted as ways in order to grow the network around Symbian. Acting in a consortium-like fashion, the alliance is enlisting other members to be compatible with the Symbian network. A series of interviews undertaken among Swedish and Finnish developers indicates that the highest concentration of developers working exclusively on Symbian is found in the Nordic region (Tee, 2004). While it allows them to gain a deeper knowledge of the platform, at the same time it poses a risk if the platform turns out to make less of an impact than expected.

\section{Operating System, GUI, and middleware}

The Symbian platform essentially consists of two components: the operating system (the Symbian OS which is currently in v9.0) and the Graphical User Interface (GUI), which provides the important graphical "shell" running on top of the OS. The main GUI's are Series 60, developed by Nokia and UIQ, developed by former Ericsson subsidiary UIQ.

Increasingly, the GUI is being regarded as a 'differentiating' factor. The two GUI's are technically incompatible: applications that are written for one GUI will not work on the other. The GUI forms - by definition - the direct interface from the handset to the user. It is important to know that the GUI can be separated from the OS, a practice known as 'porting'. ${ }^{14}$ Thus, both for the owner of the GUI and the owner of the OS, there is flexibility in terms of which system it supports. For example, it has been speculated that Nokia could,

\footnotetext{
${ }^{13} \mathrm{http}: / / w w w . s y m b i a n . c o m$

${ }^{14}$ Porting means that that a program's source code will be (partly) rewritten to fit another OS. For example, PalmSource is currently moving their OS to Linux.
} 
for financial as well as strategic reasons, port its Series 60 interface to run on top of Linux, now that it has announced a 'web tablet' which runs on the open OS. ${ }^{15}$

In addition to the separation of OS and GUI, the emergence of middleware applications is also increasingly regarded as detrimental to the take-up of the Symbian OS, and smartphones in general. The most important middleware platform in this case is Java, a programming environment created by Sun Microsystems which allows applications to run independent of an operating system. It achieves this by making use of a virtual machine that runs on top of the OS. The mobile implementation of Java, called J2ME, runs on circa $12 \%$ of all handsets ${ }^{16}$.

At the outset many predicted a standards war between Symbian OS and operating systems such as Microsoft Windows for Mobile and PalmOS. The expectation was that a major battle ground would for next generation mobile telephones would be in the operating system in the handsets, and that the major battle would pit major players-especially Nokia and Microsoft - against one another in head-to-head competition as they sought to leverage their respective positions in neighboring technologies. ${ }^{17}$ In the event, such a classic horizontal fight for dominant design has been supplanted to a significant degree by a different threat originating at a different layer. The horizontal form of rivalry is increasingly being complemented by threats especially from middleware technologies, most importantly J2ME and potentially also the GUI's themselves. The dynamics within the Symbian case show the unpredictability of the technological solidification processes. The assumption that a number of operating systems would compete head to head as in the PC industry turned out to be flawed. Instead, we see how due to developments in both the technological and market regime shape the direction of the standardization process.

The strategies of both Nokia and Microsoft, the two main actors in this process, are clear expressions of their position in their respective industries. First, Nokia being the dominant player in a vertically integrated mobile handset market, can be said to adopt an approach that might be called "intergenerational leveraging". It bundled its strength with competitors and attempted to dominate the mobile operating system market. Its dominant position ensured it could set the technological agenda in this process, having both the financial and technological resources to do this. In contrast, Microsoft being the dominant player in an adjacent market, opted for what might be called an "intertechnological leveraging" approach. It developed its own mobile OS, hoping to license it to device makers. While initially none of the top tier manufacturers were interested, it worked together with mobile operators and ODM device makers. It could also use its strength in the PC market to optimize the synchronization between critical applications (such as email) on the handset and PC. At the same time, none of these players prevented a relative outsider - Sun - to develop and license its own technology. In the case of Nokia, it has actually been one of the strongest supporters of mobile Java. Of course, Microsoft had been able to pre-empt Sun from successfully diffusing its Java technology in the PC environment, but it lacks this position in the mobile market (Garud et al, 2002).

\section{Struggle for centrality: core and periphery}

Overall, the potential of two "upper-layer" technologies, the GUI and middleware technologies, show the indeterminacy of what constitutes core and what peripheral

\footnotetext{
${ }^{15} \mathrm{http}: / /$ www. arcchart.com/blueprint/show.asp?id=374\&qtabs=99999

${ }^{16}$ Compared to $2 \%$ for the smartphone market, in 2003

${ }^{17}$ See e.g. The Industry Standard, June 2001:

http://www.findarticles.com/p/articles/mi_m0HWW/is_23_4/ai_75669918
} 
components. The core components of the PC system (first the OS, next the chipset) do not automatically establish themselves as such in other environments. In contrast, our analysis points to the constructivist nature of the solidification process. Distinctions such as core and peripheral components and degree of pleiotropy are not a complete function of technology. Instead, we perceive them as negotiated outcomes, to a certain extent driven by technological factors, but equally influenced by matters such as power differences, as well as linkages different actors maintain in trying to influence the direction of a technology.

We might think of technological trajectories and dominant designs as complementary concepts. The former alludes to co-existence, while the latter is - as implied in the term associated with dominance. Neither of these outcomes is predetermined. The same goes for the idea of pleiotropy, and the related distinction between core and periphery. Here too one cannot a priori determine which subsystems will become core components and which ones peripheral. The confusion during this negotiation process is expressed in the power struggles one commonly finds in these battles, which can be observed in terms of alliance forming and the establishment of other types of linkages.

As an alliance, Symbian demonstrates two notable types of first level dynamics. The first is that the 'standards' process builds on an existing proprietary technology owned by a single company. Psion's OS was in version 5.0 when Nokia and Ericsson entered the picture to create Symbian. The subsequent four versions developed within the alliance have codeveloped as the membership of the Symbian alliance has substantially changed. The second type of dynamic is that the newer versions substantially reflect updates to interoperate with emerging standard applications and protocols. In this sense, Symbian represents a technology that strategically gateways with an increasing number of freely available standards.

- Narrow and changing alliance membership building on top of proprietary OS (currently v9.0, starting with v5.0 developed by Psion)

- Rapidly evolving versions of OS to strategically embrace existing and emerging messaging and connectivity standards.

- Differentiation and branding of dependent User Interfaces on top of base OS:

- Series60 (Nokia) and UIQ (UIQ)

Symbian has some lessons to teach about the changing market for standards. This alliance can be seen as an attempt to capitalize on the coordinative capacity afforded by an open standard "consortium" while asserting ownership control of a company. This option was arguably taken under the original perception a potential 'standards war' between dominant players in the mobile handset market and in the PC market. This risk which would pit Nokia, Ericsson and Motorola in mobile handsets against Microsoft with its OS based position in the PC turned out not to be the VHS versus Betamax many feared.

The competitive dynamics turned out to be different (e.g. one competitor is coming from another non-native level of technology). As this became clear, the alliance evolved and major partners were lost. It also developed ways to co-opt other interested parties and link with complementary resources through licensing conditions etc. One of the main things that the Symbian case does is to illustrate strategic questions in terms of what is happening in the 'implementation environment'.

Overall, the evolution of the Symbian operating system, in the wider context of smartphone platforms, shows the complexity of anticipating the direction of standards battles. This 
particular case shows how a dominant design, specifically its core components, are very hard to predict. In addition, the appearance of dominant designs are from the outset of a "technology battle" not a given. As many important standards are based on open protocols, a situation of co-existence between platforms might also take place.

Defining dimensions of the Symbian case:

1. Institutional setting

a. Commercial alliance (privately held company) of mobile handset manufacturers, and initially also PDA hardware/software supplier Psion.

2. Time-frame

a. From 1998 to 2004, from company owned by three actors to more broadly supported alliance, into alliance dominated by one actor.

3. Characteristics of the technology

a. Component: operating system for mobile phones, consisting of base OS and User Interfaces on top of $\mathrm{i}$ t.

4. Characteristics of the market

a. Mobile phones making use of 'open' OS usually referred to as smartphones. was expected to constitute a sig nificant part of the overall handset market.

5. Characteristics of the actors

a. 'First tier' mobile handset manufacturers

b. Initially: Psion, Nokia, Ericsson and later joined by Motorola, Siemens, Samsung, Panasonic, SonyEricsson

c. Furthermore partners through various types of partnerships (S ymbian Platinum Program), Symbian Certified (Develop ers)

6. Impacts

a. Intended as (1) cost reduction in combining resources for open, scalable platform (2) allegedly, strategic alliance against dominant supplier of operating systems in PC market (Microsof t).

b. Limited impact on overall mobile handset market : Currently still a relatively small size of the overall market (less than $5 \%$ )

\section{Discussion}

It is commonly assumed that mobile communications - and the extensive standards that underpin them-develop in generations $(1 \mathrm{G}, 2 \mathrm{G}$, etc). This popular conceptualization served to promote a sense of orderly development. Thus the end of the GSM standardization process paved the way for the start of the UMTS process. This idea of stability was particularly attractive at the height of the success of the GSM standards. At this point stakeholders were eager to project their current success into future markets as they addressed already recognized improvements in the $2 \mathrm{G}$ architecture and to bootstrap neighboring competencies ('Local search') ${ }^{18}$ from their 1G NMT experiences.

At least since the last meeting of GSM created a Sub-Technical Committee to study UMPTS in October 1991, a different set of standards dynamics has increasingly challenged the stability suggested by this generational model. Here the role of standards has been changing apace. Dynamics here include new modes of organization of standards (e.g. competition between standards (e.g. Tetra versus Tetrapol); cooperation between SSBs (e.g. Parlay and

\footnotetext{
${ }^{18}$ Nelson and Winter, 1982.
} 
ETSI); alliances emulating standards consortia (e.g. Symbian); as well as other developments including the tendency to focus on middleware. Together, changes in the way standardization is organized reflects a larger evolutionary process in the organization of the sector within the volatile mobile telecoms industry.

They also pose some fundamental questions for actors including Nordic stakeholders whose interests were closely linked to the propagation of success in the $1 \mathrm{G}$ to the $2 \mathrm{G}$ era. For these, the current situation is fraught with many uncertainties. These issues manifest itself on a number of different levels where Nordic companies have a stake, including networks and infrastructure (the slow transition to 3G); devices (fluidity in the case of smartphones), and related software and middleware (Symbian). Put differently, we can observe a great deal of uncertainty, accompanied by a large number of different standards.

The Symbian case serves to illustrate that the emergence of heterogenous platforms types are changing the way alliances are built and standards-battles are waged. These platforms include "native" operating systems such as Symbian, Windows Mobile for Smartphones, and PalmOS. Next there are the middleware technologies of which J2ME is the most important in this mobile context. In addition there are the operator instigated platforms, which include Vodafone Live, i-mode, T-Mobile's T-zones, and Orange World. As most of these platforms work alongside each other, it is very difficult to anticipate how these competitional dynamics will play out. However, each platform is driven by different actors, including handset manufacturers, OS developers, and mobile network operators. Thus, depending on whether and which platform type will dominate, different industry actors are better positioned to benefit from the dominant design. For example, on the network level, we see a number of non-cellular standards (Wifi, Wimax), some of which can be considered to compete with various $3 \mathrm{G}$ use cases. Some network operators are even bypassing the first-stage roll-out of $3 \mathrm{G}$, instead waiting for the UMTS upgrade HSDPA, sometimes termed as 3.5G. ${ }^{19}$ Supporting interoperability in this environment also becomes key.

For the Nordics, Symbian was seen as a bid to leverage Nokia's and SonyEricsson's positions in light concerns that Microsoft would leverage dominant position onto the mobile market. The bid was symptomatic of the changing market for standards, involving on a one-hand disengagement in this technological area from the formal standards environment (where these actors also remained very active in the IMT 2000) and, on the other, the mimicry of a standards activity by a for-profit alliance involving actors who compete on other markets.

Mobile phone usage in Europe is still pre-dominantly voice and SMS driven and data services have not taken off as rapidly as imagined. Relatedly, smartphones were expected to become a major market segment, but have not taken off as anticipated. That said, the Symbian OS, where Nokia is a dominant actor, is currently the dominant operating system for smartphones, though mobile Java poses a potential outside threat. A key concern forward is to promote the development of services and applications for Symbian. For the Symbian platform developers, this involves strengthening the Symbian platform in terms of the applications that are considered critical ${ }^{20}$. It also involves how to get independent software developers to focus on

\footnotetext{
${ }^{19}$ Examples include T-Mobile in the Netherlands and Germany, see http://www.theregister.com/2005/07/22/hsdpa gernany/ and Telfort in the Netherlands, see http://www.nu.nl/news/569009/51/T-Mobile_begint_volgend_jaar_met_opvolger_UMTS.html

${ }^{20}$ This might include for example end-to-end email support, full compatibility with Microsoft Office applications, support for popular audio DRM standards like Apple's AAC and/or Microsoft's PlaysForSure, camera quality, and interoperability with GPS software
} 
applications for the Symbian environment. Most importantly, for Symbian as whole, is to move on from its dependence on a single customer, but rather stimulate its other licensees to mature the platform.

In this light, the mobile telecoms sector continues to undergo substantial changes. These overall industry dynamics will continue to be reflected in the evolving standards system. The Symbian case has illustrated some aspects of the dynamic link between changes in the organization of the standardization process and of the industry at large. Just as standards dynamics have played an important role in the success of Nordic actors during the early GSM era, standards are expected to play an equally important role as well in these future 'battles'. 
References

Abbate, Janet (2000). Inventing the Internet. The MIT-Press: Cambridge, Mass. $272 \mathrm{pp}$.

Abernathy, William J. and Utterback, James. M. (1978), "Patterns of Industrial Innovation", Technology review, June-July

Anderson, Philip and Tushman, Michael L. (1990). Technological Discontinuities and Dominant Designs: a Cyclical Model of Technological Change. Administrative Science Quarterly, 35:604-633.

Bresnahan, TF \& Greenstein, S (1997). Technical Progress and Co-Invention in Computing and in the Use of Computers." Brookings Papers on Economics Activity: Microeconomics: pp. $1-78$.

Clark, K. B (1985). "The Interaction of Design Hierarchies and Market Concepts in Technological Evolution." Research Policy, 14, no. 5: p235-251.

Cohn, M. (2001) “Colly Myers” Internet World; 06/15/2001, Vol. 7 Issue 12, p38, 8p

David, Paul A. (1995) Standardization policies for network technologies: the flux between freedom and order revisited. In Hawkins, R., R. Mansfield \& J. Skea (Eds.). (1995) Standards, innovation and competitiveness: Edward Elgar.

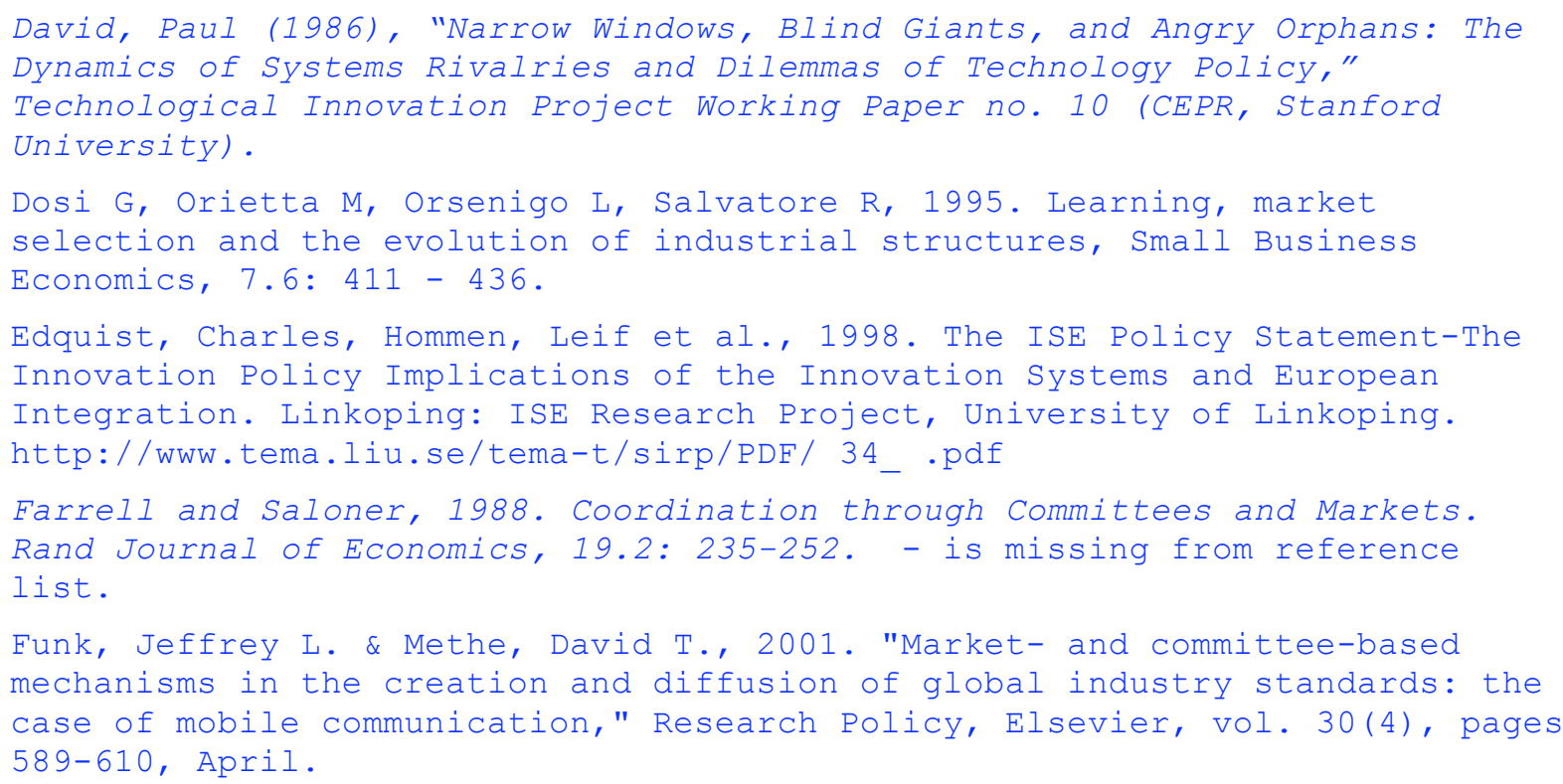

Gaillard, John. Industrial standardization: its principles and application. (H. W. Wilson Co. New York, 1934.

Garud, R. S. Jain, A. Kumaraswamy (2002). “Institutional entrepreneurship in the sponsorship of common technological standards: The case of Sun Microsystems and Java”, Academy of Management Journal, 45(1), 196 - 214.

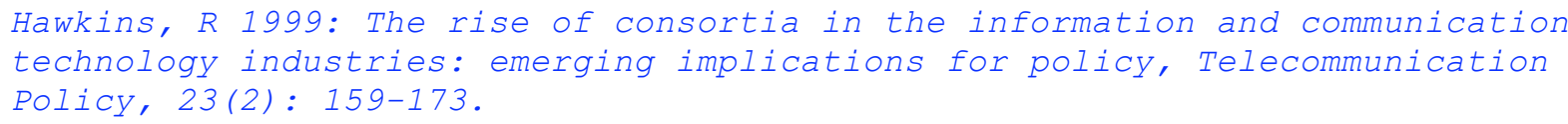


Glimstedt, Henrik (2001) Competitive dynamics of technological standardization: The case of third generation cellular communications Industry and Innovation, Apr 2001.

Hillebrand, F. (ed). GSM and UMTS: the creation of global mobile communications. John Wiley \& Sons: England.

Iversen, Eric. (1999) Standardization and Intellectual Property Rights: ETSI's controversial search for new IPR-procedures. SIIT Proceedings, IEEE publications. Reprinted in Sherrie Bolin (2002). The Standards Edge. Bolin Communications: Ann Arbor, MI.

Iversen, Eric J. \& Richard Tee (2005). "Standards dynamics in the mobile communication area: Three cases", conference paper INTEROP-ESA Workshop "Interoperability Standards - Implementation, Dynamics, and Impact", February 22, 2005

Kim, CW and Keun Lee. (2001)Innovation, Technological Regimes and Organizational Selection in Industry Evolution: A "History Friendly Model" of the DRAM industry. http://dasan.snu.ac.kr/ ecores/activity/paper/no.46.PDF

Langlois, Richard N. and Paul L. Robertson, Firms, Markets, and Economic Change: A Dynamic Theory of Business Institutions (London, 1995).

Langlois, Richard N. “The Vanishing Hand: The Changing Dynamics of Industrial Capitalism," Industrial and Corporate Change 12 (April 2003): 351-85, 376.

Langlois, Richard N. “Technological Standards, Innovation, and Essential Facilities: Toward a Schumpeterian Post-Chicago Approach," in Dynamic Competition and Public Policy: Technology, Innovation, and Antitrust Issues, ed. Jerry Ellig (New York and Cambridge, 2001), 193-228. As

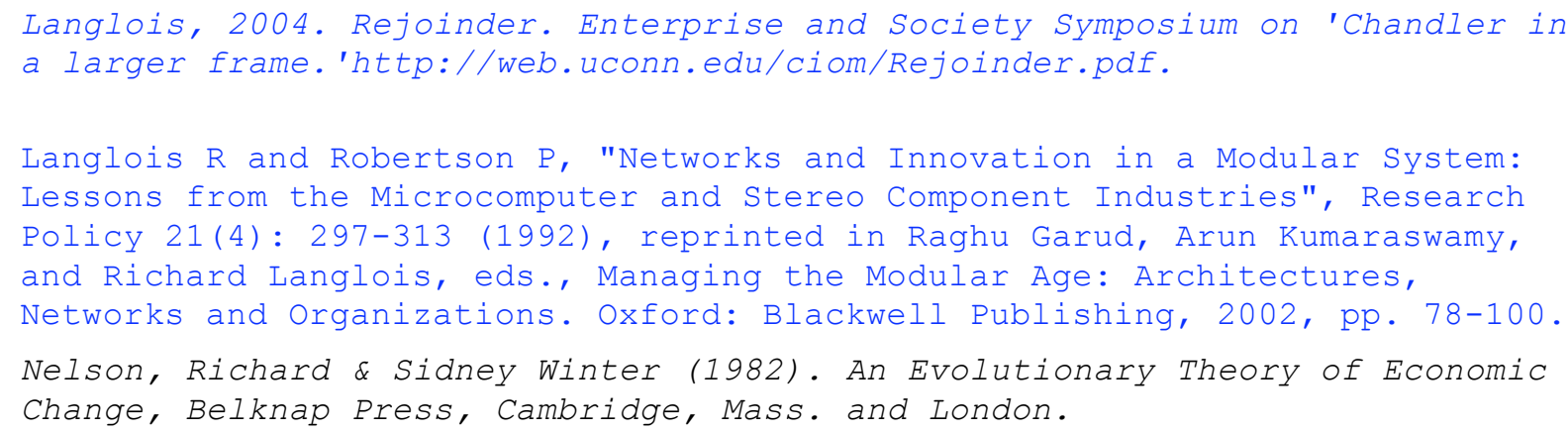

Marks \& Hebner (2004). The Standards Edge: Dynamic Tension. S Bolin (ed)

Metcalfe, J. S. \& Miles, Ian, 1994. "Standards, selection and variety: an evolutionary approach," Information Economics and Policy, Elsevier, vol. 6(3), pages 243-268, 12.

Murmann, J.P., Frenken, K. (2002). Towards a systematic framework for research on dominant designs, technological innovations, and industrial change, Papers on Economics and Evolution 0212, working paper, Max Planck Institute, Jena.

Nelson, Richard The co-evolution of technology, industrial structure, and supporting institutions. Industrial and Corporate Change, 1994 
Rosenkopf, L. and M.L. Tushman. (1994) "The Coevolution of Technology and Organization.". In Baum, J. and J. Singh (eds.), Evolutionary Dynamics of Organizations, Oxford.

Shapiro, C. (2000) "Competition Policy in the Information Economy," in Competition Policy Analysis, Einar Hope, ed., 2000, Routledge Studies in the Modern World Economy.

Schmidt, S (1992). Negotiating Technical Change through Standards: technical coordination in markets and committees, Cologne: MPLFG Discussion Paper.

Schmidt, Susanne K. \& Raymund Werle (1998). Coordinating technology: Studies in the International Standardization of Telecommunications. MIT:

Cambridge, Mass.

Schumpeter, Joseph (1934) The Theory of Economic Development. An Inquiry into Profits, Capital, Credit, Interest, and the Business Cycle, New Brunswick, NJ: Transaction Publishers. (Trans. R. Opie).

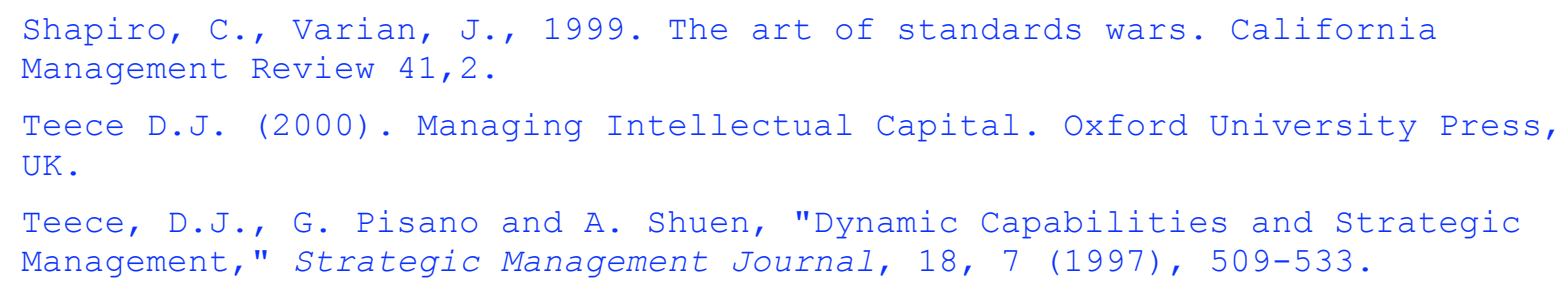

Tee, Richard (2004). "Dominant designs in the emerging market for smartphones", ESST thesis, University of Maastricht

Tushman, M.L., and J.P. Murmann (1998) 'Dominant designs, technology cycles, and organizational outcomes' in Research in organizational behavior. Anonymous, 231-266. Greenwich, CT: JAI Press.

Utterback, J., (1994) Mastering the Dynamics of Innovation. Harvard Business School Press, Harvard.

Vercoulen \& van Wegberg, 1999. Standard selection modes in dynamic, complex industries: creating hybrids between market selection and negotiated selection of standards. SIIT Proceedings of the 1st IEEE Conference on Standardisation and Innovation in Information Technology SIIT '99, in Aachen, Germany, September 15-17, 1999.

Werle, Raymund (2000). Institutional aspects of standardizaiton: jurisdictional conflicts and the choice of standardization organizations. MPLFG Discussion Paper 00/1.

Winter, S.G. (1984), 'Schumpeterian Competition in Alternative Technological Regimes', Journal of Economic Behavior and Organization, Vol. 5, 287-320. 